University of Nebraska - Lincoln

DigitalCommons@University of Nebraska - Lincoln

Faculty Papers and Publications in Animal

Science

Animal Science Department

2010

\title{
Effects of Sorting Steers by Body Weight into Calf-Fed, Summer Yearling, and Fall Yearling Feeding Systems
}

D. R. Adams

University of Nebraska-Lincoln

T. J. Klopfenstein

University of Nebraska-Lincoln, tklopfenstein1@unl.edu

G. E. Erickson

University of Nebraska-Lincoln, gerickson4@unl.edu

W. A. Griffin

University of Nebraska-Lincoln

Matt K. Luebbe

University of Nebraska-Lincoln, mluebbe2@unl.edu

See next page for additional authors

Follow this and additional works at: https://digitalcommons.unl.edu/animalscifacpub

Part of the Animal Sciences Commons

Adams, D. R.; Klopfenstein, T. J.; Erickson, G. E.; Griffin, W. A.; Luebbe, Matt K.; Greenquist, Matthew A.; and Benton, J. R., "Effects of Sorting Steers by Body Weight into Calf-Fed, Summer Yearling, and Fall Yearling Feeding Systems" (2010). Faculty Papers and Publications in Animal Science. 755.

https://digitalcommons.unl.edu/animalscifacpub/755

This Article is brought to you for free and open access by the Animal Science Department at DigitalCommons@University of Nebraska - Lincoln. It has been accepted for inclusion in Faculty Papers and Publications in Animal Science by an authorized administrator of DigitalCommons@University of Nebraska - Lincoln. 


\section{Authors}

D. R. Adams, T. J. Klopfenstein, G. E. Erickson, W. A. Griffin, Matt K. Luebbe, Matthew A. Greenquist, and J. R. Benton 


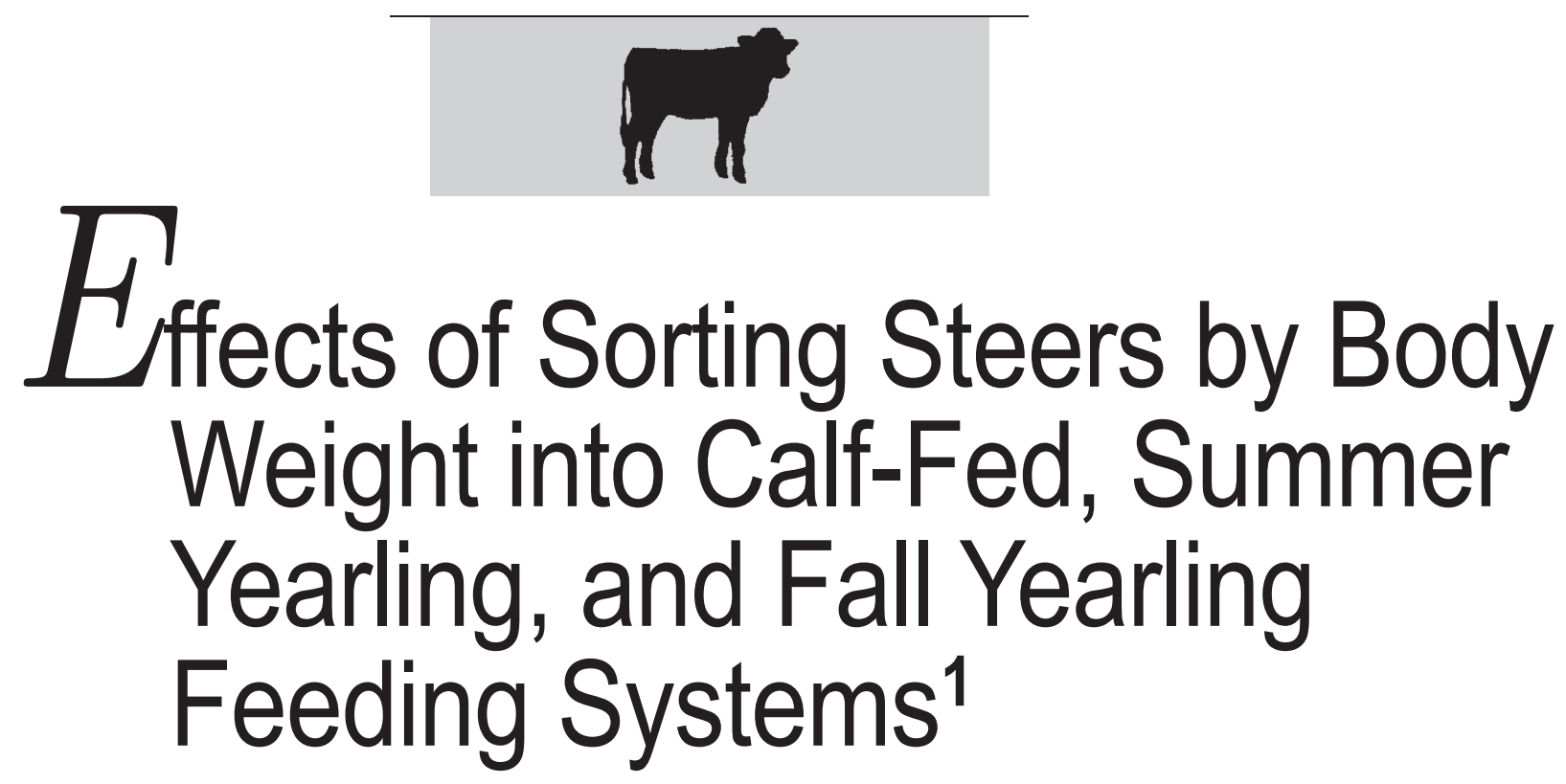

\author{
D. R. Adams, T. J. Klopfenstein, ${ }^{2}$ G. E. Erickson, PAS, W. A. Griffin, PAS, M. K. Luebbe, \\ M. A. Greenquist, PAS, and J. R. Benton, PAS \\ Department of Animal Science, University of Nebraska, Lincoln 68583
}

\begin{abstract}
Two years of data (288 steers/yr) were used to determine if sorting cattle by $B W$ into different production systems would decrease overweight carcasses $(>431 \mathrm{~kg})$ and hot carcass weight ( $\mathrm{HCW}$ ) variation. At receiving, steers were assigned randomly into sorted or unsorted groups ( $n=144$ steers/group). Within a group, steers were assigned to 1 of 3 feeding times: 1) calf-fed (entering the feedlot at receiving), 2) summer yearling (grazed during winter and entering the feedlot in May) and 3) fall yearling (grazed during winter and summer and entering the feedlot in September). Unsorted steers were assigned randomly to a feeding time. Sorted steers were assigned to a feeding time based on $B W$, with the heaviest one-third fed as calf-fed steers and the remaining steers grazing in the winter. After winter grazing, the heaviest one-half of the remaining sorted steers were fed as summer yearlings and the lightest one-half grazed summer grass

\footnotetext{
${ }^{1}$ A contribution of the University of Nebraska Agricultural Research Division, supported Act.

${ }^{2}$ Corresponding author: tklopfenstein1@unl.
} in part by funds provided through the Hatch edu
\end{abstract}

and entered the feedlot in September. On feedlot entry, steers were assigned randomly to 6 pens/treatment. This experiment was analyzed as a completely randomized design with a $2 \times 3$ factorial arrangement of treatments and with pen as the experimental unit. By design, interactions $(P<0.05)$ were observed for initial feedlot $B W$ and $H C W$. In addition, interactions $(P<0.05)$ were observed for $G: F$ and percentage of overweight carcasses. Sorted fall yearlings had fewer overweight carcasses $(6.40$ vs. 35.42\%). Regardless of whether they were sorted or unsorted, calf-fed steers and summer yearlings did not produce many overweight carcasses. Sorting into a production system decreased $\mathrm{HCW}$ variation and percentage of overweight carcasses.

Key words: carcass characteristic, feedlot cattle, sorting

\section{INTRODUCTION}

Ruminants have the ability to convert cellulose into energy and protein (Van Soest, 1994); therefore, they are able to graze in areas where cultivation or harvesting of forages is not feasible (Oltjen and Beckett, 1996). In terms of beef consumption, a constant supply of beef is critical, meaning cattle must be slaughtered throughout the year. To achieve a year-round beef supply, 2 major types of production systems are used: extensive and intensive (Griffin et al., 2007). Extensive systems use forage-based programs to grow cattle before they enter the feedlot. In extensive systems, cattle enter the feedlot after backgrounding. This can be after winter grazing or summer grazing. In intensive systems, cattle are placed in the feedlot directly after weaning and fed a high-concentrate diet until slaughter.

The cattle population is diverse in terms of BW and frame (Dolezal et al., 1993). This is important when choosing production systems to maximize profit. If large-framed cattle are placed in an extensive system, they may become overweight and receive discounts, thus decreasing profitability (Vieselmeyer, 1993). Furthermore, smaller framed cattle would be better suited to an extensive system, which allows the animal to grow. If smaller framed animals are placed directly into an intensive system, they risk becoming overconditioned at a less than ideal BW (Turgeon, 1984). If these smaller framed cattle are allowed to grow in an extensive system and then 


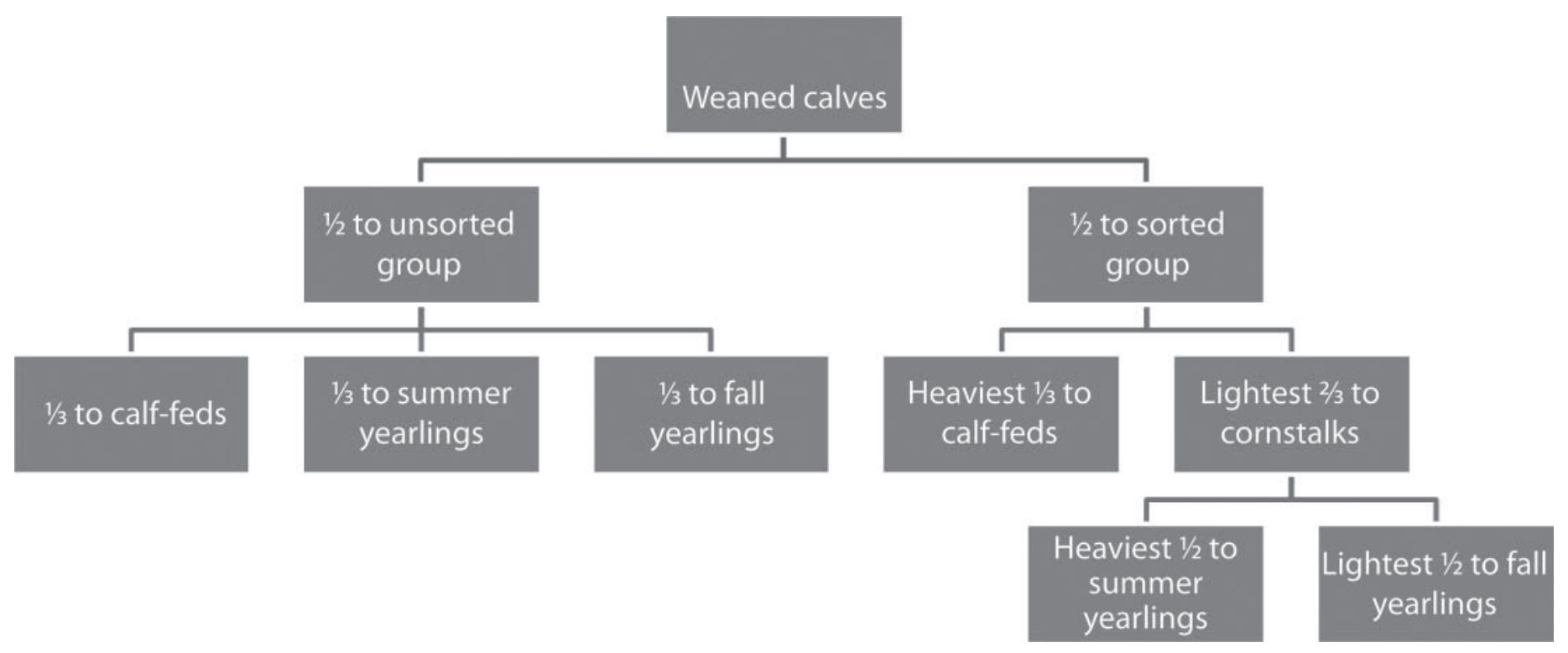

Figure 1. Experimental design of sorting.

placed into the feedlot, they will produce larger carcasses without being excessively fat (Griffin et al., 2007).

Previous research has shown that calf-fed animals have greater G:F, more days on feed, and lighter hot carcass weights (HCW) compared with yearlings finished in the feedlot (Turgeon, 1984; Lewis et al., 1989; Griffin et al., 2007). In these studies, at the time of receiving, heavier cattle were sorted into calf-fed systems and lighter cattle were placed into yearling systems. Therefore, the objective of this study was to determine the effects of sorting or not sorting genetically similar cattle by BW into 3 different production systems (calffed steers, summer yearlings, and fall yearlings) and to determine feedlot performance and carcass characteristics.

\section{MATERIALS AND METHODS}

\section{Experiments}

This experiment was a 2-yr study that evaluated sorting steers into 3 different production systems: calf-fed steers, summer yearlings, and fall yearlings. In the first year, 288 English-cross steers $(250 \pm 37 \mathrm{~kg})$ were purchased from Nebraska ranches and delivered directly to the University of Nebraska Research Feedlot at Mead. There were 224 steers from one ranch
$(255 \pm 40 \mathrm{~kg})$ and 64 steers from a second ranch $(223 \pm 19 \mathrm{~kg})$. In the second year, 288 English-cross steers $(242 \pm 23 \mathrm{~kg})$ were purchased from Nebraska sale barns and delivered to the University of Nebraska Research Feedlot. There were 167 steers in one purchase $(243 \pm 24 \mathrm{~kg})$ and 121 in a second purchase $(240 \pm 21 \mathrm{~kg})$. At the time of arrival, cattle were dewormed (Dectomax injectable, Pfizer, New York, NY), vaccinated with a killed vaccine for clostridial diseases (Ultrabac 7 with Somnus, Pfizer), vaccinated against respiratory disease (Bovishield Gold, Pfizer), and ear tagged. After processing, the steers were placed on bromegrass pastures and supplemented with hay and wet corn gluten feed [Sweet Bran (SB), Cargill, Blair, NE] as needed for 28 d. At the end of the receiving period, steers were limit fed a basal diet of $50 \%$ SB and $50 \%$ alfalfa hay (DM basis) for $5 \mathrm{~d}$ at $2 \%$ of BW. At the end of the limit-feeding period, steers were assigned randomly to either the sorted group $(\mathrm{n}=144 / \mathrm{yr})$ or the unsorted group $(\mathrm{n}=144 / \mathrm{yr})$. In the unsorted group, steers were assigned randomly to 1 of the 3 production systems. The sorted steers were sorted into the different production systems based on BW at different times of the year. The heaviest one-third of the cattle in the sorted group were placed into the calf-fed system. The remaining sorted cattle were allowed to graze cornstalks throughout the winter.

At the end of the wintering phase, the heaviest one-half of the remaining sorted steers were placed into the summer yearling production system and the lightest one-half were then placed into the fall yearling production system (Figure 1). Each year, there were 8 animals/pen, with 6 replications of sorted or unsorted pens per finishing period. This resulted in a total of 12 pens for each system treatment. The diets for the 3 different feeding periods were the same within a year (Table 1). Comparisons were made among the 3 different production systems.

\section{Calf-Fed Steers}

Calves were limit fed for $5 \mathrm{~d}$ and $\mathrm{BW}$ were taken on $\mathrm{d} 0$ and 1 . In this study, the unsorted calf-fed steers were assigned randomly to the calf-fed system and not assigned based on BW. In the sorted group, the heaviest one-third were placed into the calf-fed system. This was based on d 0 BW after being limit fed. Cattle were stratified by BW and then assigned randomly to pens. In yr 1 and 2, November 22, 2005, and November 14, 2006, respectively, were d 0 . In yr 1 , steers were initially implanted with Synovex S (Fort Dodge Animal 
Health, Overland Park, KS) and reimplanted on d 71 with Revalor S (Intervet Inc., Millsboro, DE). In yr 2, steers were initially implanted with Synovex Choice (Fort Dodge Animal Health) and reimplanted with Synovex Choice (Fort Dodge Animal Health) on d 82. The calf-fed steers were fed for 167 and $196 \mathrm{~d}$ in yr 1 and 2 , respectively. Steers were slaughtered on May 9, 2006, and on May 30, 2007, in yr 1 and 2, respectively.

\section{Summer Yearlings}

At trial initiation, steers were limit fed $50 \%$ SB and $50 \%$ alfalfa hay (DM basis) for $5 \mathrm{~d}$ at $2 \%$ of BW. After limit feeding, steer BW were collected. The unsorted group of summer yearlings was already assigned to treatment based on the random sort at the time of trial initiation. After BW were collected, steers were transported to cornstalks. Cattle grazed cornstalks over the winter months and were supplemented with $2.27 \mathrm{~kg} \mathrm{SB} /$ animal per day (DM basis) to achieve a BW gain of 0.68 $\mathrm{kg} / \mathrm{d}$ (Jordan, 2000). Steers grazed cornstalks for 153 and $156 \mathrm{~d}$ in yr 1 and 2 , respectively. At the end of the cornstalk-grazing period, steers were limit fed 50\% SB and 50\% alfalfa hay (DM basis) for 5 consecutive days at $2 \%$ of BW. Limit-fed BW were collected on 2 consecutive days. Assignment of cattle to the sorted summer yearling system was determined based on the 2-d average BW, with the heaviest one-half of the sorted group being placed into the summer yearling system. Cattle were then allowed to graze bromegrass from April to May. Cattle grazed bromegrass for 35 and $48 \mathrm{~d}$ in yr 1 and 2, respectively. Steers assigned to the summer yearling system were then separated from the fall yearlings and limit fed $50 \%$ SB and $50 \%$ alfalfa hay (DM basis) for $5 \mathrm{~d}$ at $2 \%$ of BW. After limit feeding, BW were collected for 2 consecutive days. The $\mathrm{d} 1 \mathrm{BW}$ were $\mathrm{d} 0$ of the finishing period. Day 0 BW were used to assign cattle randomly to pens so that the pen average BW were similar within the sorted and unsorted groups. Body weights from d 0 and 1 were averaged to obtain the initial feedlot entry BW for the summer yearlings.

May 30, 2006, and June 6, 2007, were $\mathrm{d} 0$ for the summer yearling finishing period in yr 1 and 2, respectively. In yr 1, cattle were implanted with Revalor S (Intervet Inc.). In yr 2, cattle were implanted with Synovex Choice (Fort Dodge Animal Health) on d 48. Steers in yr 1 were fed for $133 \mathrm{~d}$ and slaughtered on October 11, 2006. Steers in yr 2 were fed for $145 \mathrm{~d}$ and slaughtered on October 30, 2007.

\section{Fall Yearlings}

The unsorted fall yearlings were assigned based on the initial sort at the time of trial initiation. The sorted fall yearlings were determined based on $\mathrm{BW}$ at the end of the winter grazing period. The fall yearlings were limitfed $50 \%$ SB and $50 \%$ alfalfa hay (DM basis) for $5 \mathrm{~d}$ at $2 \%$ of $\mathrm{BW}$ at the time of arrival. After limit feeding, BW was taken on 2 consecutive days and steers were placed onto cornstalks for the winter months and fed $2.27 \mathrm{~kg}$ $\mathrm{SB}$. This was to achieve a BW gain of $0.68 \mathrm{~kg} / \mathrm{d}$ (Jordan, 2000) while grazing cornstalks. At the end of the winter grazing period, cattle were then limit fed $50 \%$ SB and $50 \%$ alfalfa hay (DM basis) for $5 \mathrm{~d}$ at $2 \%$ of BW. After limit feeding, BW were collected on 2 consecutive days. Steers were then placed onto bromegrass to graze before being branded and implanted with Revalor G (Intervet Inc.). Steers were transported to the University of Nebraska Barta Brothers Ranch near Rose to graze Sandhills native range over the summer months. The summer grazing period on the bromegrass and Sandhills was considered 1 grazing period. The fall yearlings grazed pasture for 149 and $152 \mathrm{~d}$ for yr 1 and 2 , respectively.

The fall yearlings were then transported back to the research feedlot near Mead, Nebraska, and limit fed $50 \% \mathrm{SB}$ and $50 \%$ alfalfa hay (DM basis) for $5 \mathrm{~d}$ at $2 \%$ of BW. After limit feeding, steers were weighed for 2 consecutive days (d 0 and 1 of the finishing period). Cattle were assigned

\section{Table 1. Diet composition for the finishing period for each year $^{1}$

\begin{tabular}{lcc} 
Ingredient & yr 1 & yr 2 \\
\hline Dry-rolled corn & 33.75 & 33.75 \\
High-moisture corn & 33.75 & 33.75 \\
Wet distillers grains & 15.00 & 20.00 \\
$\quad$ plus solubles & & \\
Alfalfa & 7.50 & 7.50 \\
Molasses & 5.00 & - \\
Supplement $^{2}$ & 5.00 & 5.00
\end{tabular}

${ }^{1}$ Amounts of ingredients presented as percentage inclusion on a DM basis.

${ }^{2}$ Supplement contained $30 \mathrm{~g} /$ ton of monensin (Elanco Animal Health, Greenfield, IN) and $90 \mathrm{mg} / \mathrm{animal}$ daily of tylosin (Elanco Animal Health).

randomly to pens based on d 0 BW. Pen average BW within the sorted and unsorted groups were similar. Day 0 of the finishing period was September 21, 2006, and September 19, 2007, for yr 1 and 2, respectively. During yr 1, cattle were implanted with Revalor S (Intervet Inc.) on d 23 , and in yr 2, cattle were implanted with Revalor S (Intervet Inc.) on d 28. The fall yearlings were fed for 116 and $132 \mathrm{~d}$ during yr 1 and 2, respectively. The fall yearlings in yr 1 were slaughtered on January 16, 2007, and on January 30, 2008, in yr 2.

For all treatments, final BW was determined using $\mathrm{HCW}$ and a standard dressing percentage of $63 \%$. A standard dressing percentage was used because only the carcass has value. Furthermore, using HCW reduces the differences observed in the live performance caused by differences in gut fill from live animals. Steers were slaughtered at a commercial packing plant. On the day of slaughter, the carcasses were identified, and liver scores and HCW were collected. After a 48-h chill, 12th-rib backfat and LM area were measured. The USDA called marbling score was also recorded as it was scored by a USDA grader at the plant. The USDA YG was calculated using the following equation: $\mathrm{YG}=$ $2.5+(6.35 \times$ fat thickness, $\mathrm{cm})+$ 
Table 2. Simple effects of sorting (sorted vs. unsorted) and production system (calf-fed steers, summer yearlings, and fall yearlings) on feedlot performance

\begin{tabular}{|c|c|c|c|c|c|c|c|c|}
\hline \multirow[b]{2}{*}{ Item } & \multicolumn{3}{|c|}{ Sorted } & \multicolumn{3}{|c|}{ Unsorted } & \multicolumn{2}{|r|}{$P$-value } \\
\hline & Calf-fed & Summer & Fall & Calf-fed & Summer & Fall & System & System $\times$ sorting ${ }^{1}$ \\
\hline Initial BW, ${ }^{2} \mathrm{~kg}$ & $294^{d}$ & $360^{c}$ & $394^{b}$ & $261^{\mathrm{e}}$ & $358^{c}$ & $420^{\mathrm{a}}$ & & $<0.01$ \\
\hline Initial BW SD, kg & 22 & 15 & 24 & 26 & 33 & 43 & & - \\
\hline $\mathrm{ADG}, \mathrm{kg} / \mathrm{d}$ & $1.61^{b}$ & $1.85^{\mathrm{ab}}$ & $1.88^{\mathrm{ab}}$ & $1.60^{\mathrm{b}}$ & $1.86^{\mathrm{ab}}$ & $1.94^{\mathrm{a}}$ & $<0.01$ & 0.09 \\
\hline DMI, kg/d & $9.45^{d}$ & $11.49^{c}$ & $12.29^{b}$ & $9.12^{\mathrm{d}}$ & $11.37^{c}$ & $13.15^{\mathrm{a}}$ & & $<0.01$ \\
\hline $\mathrm{G}: \mathrm{F}$ & $0.170^{\mathrm{b}}$ & $0.161^{\mathrm{b}}$ & $0.153^{c}$ & $0.179^{a}$ & $0.164^{b}$ & $0.147^{c}$ & & 0.02 \\
\hline
\end{tabular}

${ }^{a-e}$ Means within a row with different superscripts are statistically different.

${ }^{1} P$-value for production system $\times$ sorting interaction.

${ }^{2}$ Initial BW $=$ steer BW at feedlot entry.

$(0.0017 \times \mathrm{HCW}, \mathrm{kg})+(0.2 \times \mathrm{KPH}$, $\%)-\left(2.06 \times\right.$ LM area, $\left.\mathrm{cm}^{2}\right)($ Boggs and Merkel, 1993).

\section{Statistical Analysis}

Data from this study were first analyzed as a completely randomized design with a $2 \times 2 \times 3$ factorial arrangement of treatments using the MIXED procedure of SAS (SAS Institute Inc., Cary, NC). Feedlot pen was the experimental unit. The model included feeding period, sorted versus unsorted, year, feeding period by sorted versus unsorted, feeding period by year, sorted versus unsorted by year, and feeding period by sorted versus unsorted by year. There were no significant interactions with year; therefore, data from both years were pooled and analyzed as a completely randomized design with a $2 \times 3$ factorial arrangement of treatments using the MIXED procedure of SAS. Year was included as a random effect in the model. Least squares means were separated using the least significant difference method when a significant $(P<0.05)$ treatment $F$-test was detected. If there was not a significant interaction, main effects were reported. If there was a significant interaction, the simple effects were reported.

\section{RESULTS AND DISCUSSION}

\section{Feedlot Performance}

The initial BW at the time of receiving was not different between the sorted and unsorted groups within a

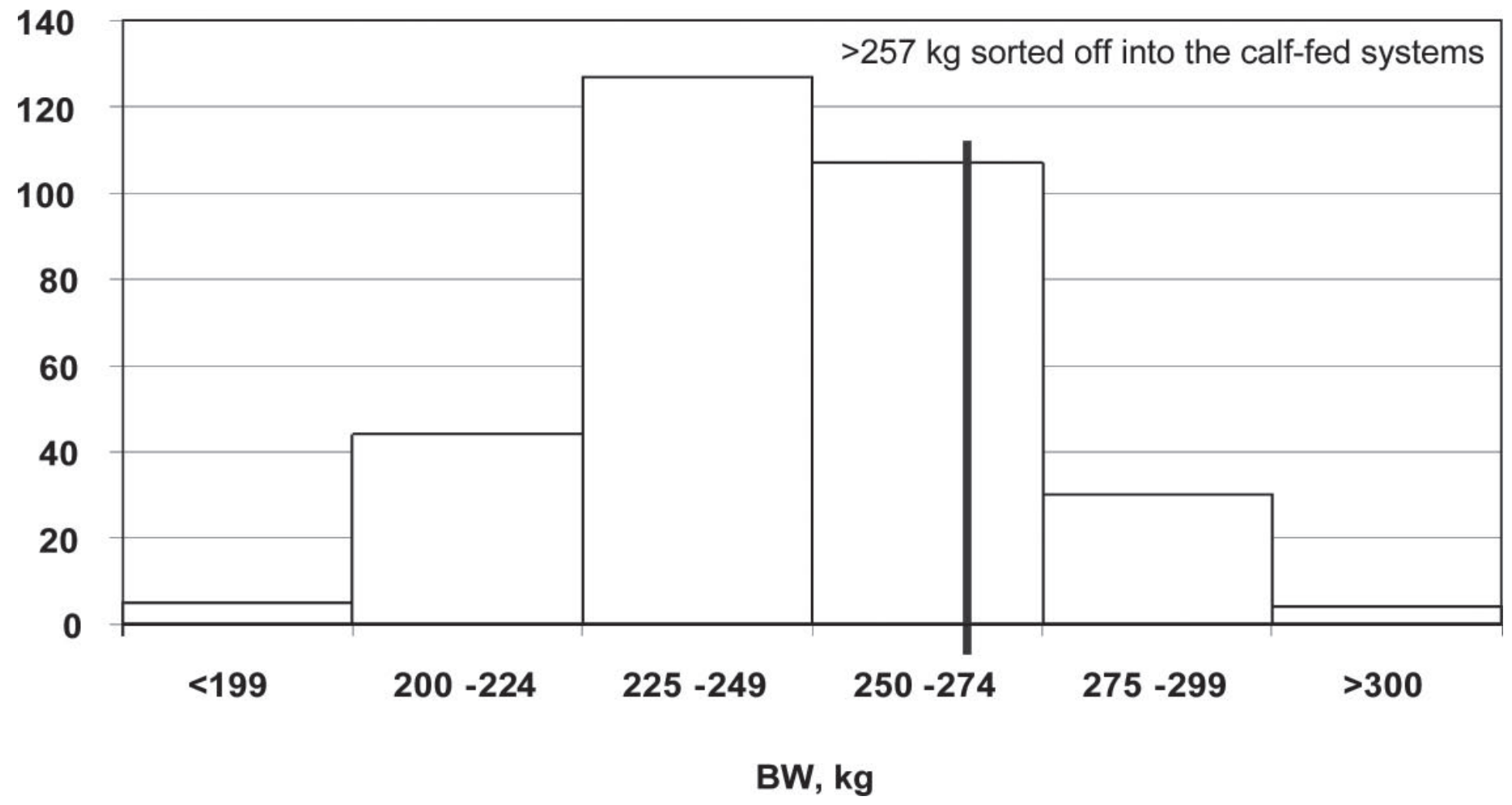

Figure 2. The BW distribution for steers at the time of arrival to the research feedlot for yr 2. 


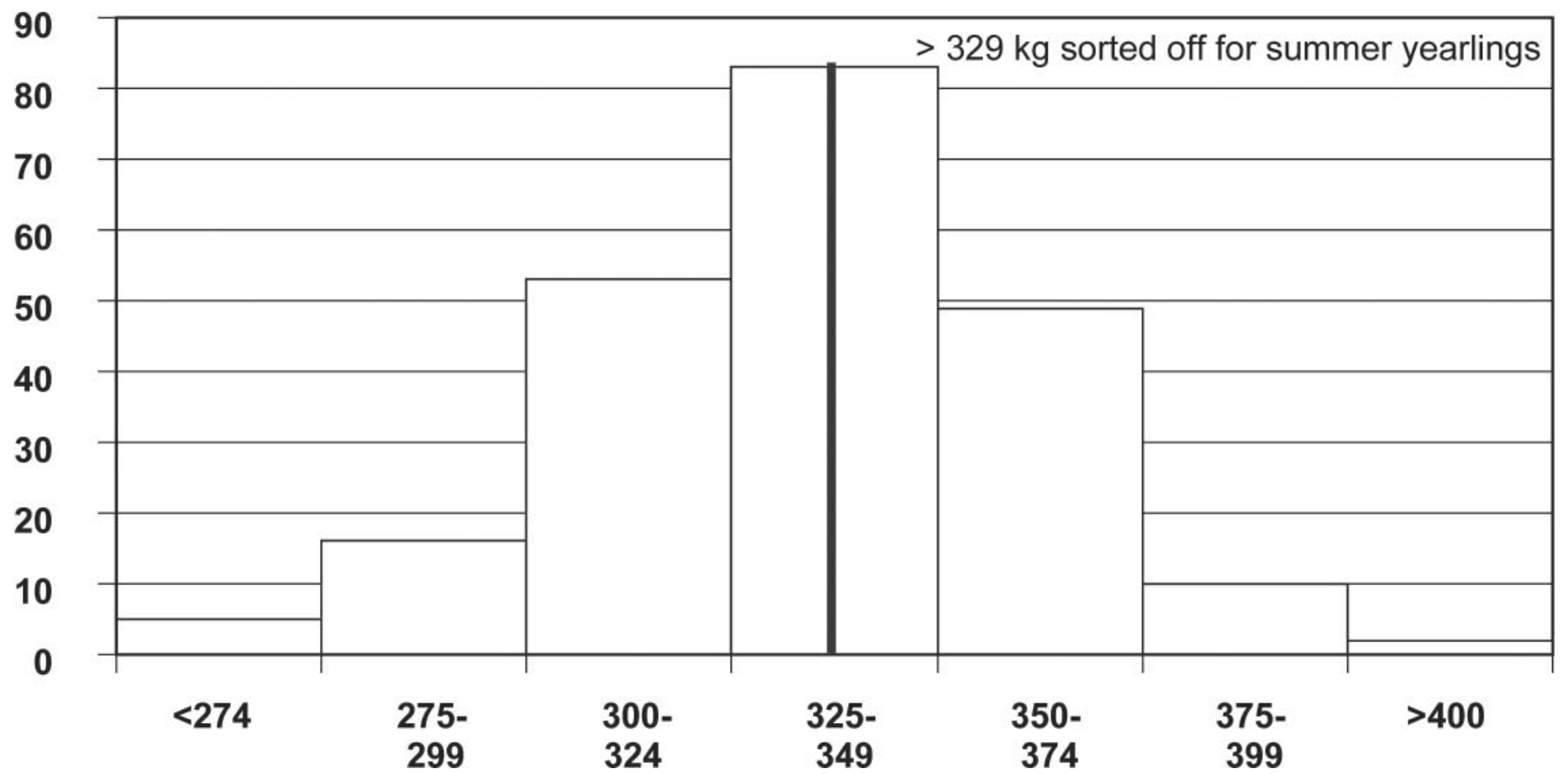

Figure 3. Body weight distribution for steers after grazing cornstalks over the winter months for yr 2.

year $(P>0.16)$. In yr 1 , the sorted group averaged $273 \mathrm{~kg}$ compared with $269 \mathrm{~kg}$ for the unsorted group. In yr 2, the sorted group had an average BW of $249 \mathrm{~kg}$ and the unsorted average was $248 \mathrm{~kg}$. The design of the study was to assign the steers randomly into the sorted and unsorted groups, thereby making the 2 groups similar. There was a significant interaction between the feeding periods and sorted versus unsorted treatments $(P<0.01)$ for initial feedlot BW

(Table 2). The sorted calf-fed steers were $33 \mathrm{~kg}$ heavier than the unsorted calf-fed steers. This was because the heaviest steers in the sorted group were placed in the calf-fed system. The unsorted group was assigned randomly into the calf-fed system. There was no difference between the sorted and unsorted summer yearlings with the initial feedlot BW of 360 and $358 \mathrm{~kg}$, respectively $(P>0.30)$. The fall yearlings were different between the sorted and unsorted groups $(P<$ 0.01). The unsorted group was significantly heavier, by $27 \mathrm{~kg}$. This was due to sorting the heaviest steers as calf-fed steers and summer yearlings in the sorted group.

Steers that were in the sorted fall yearlings were the lightest one-half af- ter grazing cornstalks. In the unsorted group, steers were assigned randomly to the group, so some of the larger steers that would normally be placed into a calf-fed system were placed into the fall yearling system. At the time of arrival in the fall, steer BW were normally distributed (Figure 2). By removing the heaviest one-third, the distribution was skewed to the right, but it returned to a normal distribution after the cattle grazed cornstalks over the winter months (Figure 3). The initial feedlot BW was according to the study design and showed that the objective was achieved.

The SD was also calculated from the initial feedlot BW. In all 3 feeding periods, the sorted steers had a numerically lower value. The SD for the sorted calf-fed steers was $22 \mathrm{~kg}$, compared with $26 \mathrm{~kg}$ for the unsorted calf-fed steers. The SD for the sorted summer yearlings was $15 \mathrm{~kg}$, whereas the SD for the unsorted summer yearlings was $33 \mathrm{~kg}$. In the fall yearlings, the SD for the sorted group was 24 $\mathrm{kg}$, compared with $43 \mathrm{~kg}$ for the unsorted group.

The system $\times$ sorted versus unsorted interaction was not significant $(P=0.80)$ for ADG; therefore, only the main effects of sorting and system are discussed. The calf-fed steers had the lowest ADG $(1.62 \mathrm{~kg} / \mathrm{d})$, followed by the summer yearlings $(1.86 \mathrm{~kg} / \mathrm{d})$. The fall yearlings had the highest ADG $(1.91 \mathrm{~kg} / \mathrm{d})$, which was not different from that of the summer yearlings $(P>0.47)$. Previous research (Griffin et al., 2007) has shown that calf-fed steers have a lower ADG compared with fall yearlings, and the summer yearlings would be expected to be intermediate. A significant interaction between the feeding periods and sorted versus unsorted $(P<0.01)$ treatments was observed for daily DMI. There was no difference between the sorted and unsorted groups of calf-fed steers and summer yearlings; however, there was a difference between the sorted and unsorted fall yearlings. The unsorted fall yearlings consumed $0.86 \mathrm{~kg}$ more daily than the sorted fall yearlings. This is likely related to the BW of the cattle within each group. When daily DMI was compared on a percentage of BW, only small numerical differences were observed. The sorted calf-fed steers had a daily DMI of $2.15 \%$ of $\mathrm{BW}$, and the unsorted calf-fed steers had a DMI of $2.22 \%$. In the summer yearlings, the sorted group was at $2.34 \%$ of $\mathrm{BW}$, compared 
Table 3. Simple effects of sorting (sorted vs. unsorted) and production system (calf-fed steers, summer yearlings, and fall yearlings) on carcass characteristics

\begin{tabular}{|c|c|c|c|c|c|c|c|c|}
\hline \multirow[b]{2}{*}{ Item } & \multicolumn{3}{|c|}{ Sorted } & \multicolumn{3}{|c|}{ Unsorted } & \multicolumn{2}{|r|}{$P$-value } \\
\hline & Calf-fed & Summer & Fall & Calf-fed & Summer & Fall & System & System $\times$ sorting ${ }^{1}$ \\
\hline $\mathrm{HCW},{ }^{2} \mathrm{~kg}$ & $368^{d}$ & $389^{c}$ & $397^{b}$ & $351^{\mathrm{e}}$ & $388^{c}$ & $417^{a}$ & & $<0.01$ \\
\hline $\mathrm{HCW}$ SD, ${ }^{3} \mathrm{~kg}$ & 26 & 19 & 28 & 30 & 30 & 40 & & - \\
\hline Fat, cm & 1.39 & 1.44 & 1.20 & 1.32 & 1.35 & 1.26 & 0.03 & 0.32 \\
\hline LM area, $\mathrm{cm}^{2}$ & $86.6^{a}$ & $82.4^{\mathrm{b}}$ & $86.6^{a}$ & $83.8^{\mathrm{b}}$ & $81.5^{\mathrm{b}}$ & $89.1^{\mathrm{a}}$ & & 0.03 \\
\hline Marbling $^{4}$ & 572 & 515 & 565 & 565 & 514 & 588 & $<0.01$ & 0.09 \\
\hline Carcasses $>431 \mathrm{~kg}, \%$ & $3.27^{c}$ & $2.08^{c}$ & $6.40^{\mathrm{bc}}$ & $1.04^{\mathrm{c}}$ & $10.42^{b}$ & $35.42^{\mathrm{a}}$ & & $<0.01$ \\
\hline Carcasses $>454 \mathrm{~kg}, \%$ & $1.19^{b}$ & $0.00^{\mathrm{b}}$ & $1.04^{\mathrm{b}}$ & $0.00^{\mathrm{b}}$ & $2.08^{b}$ & $17.71^{\mathrm{a}}$ & & $<0.01$ \\
\hline
\end{tabular}

${ }^{\mathrm{a}-\mathrm{e} M e a n s}$ within a row with different superscript are statistically different.

${ }^{1} P$-value for sorting by production systems interaction.

${ }^{2} \mathrm{HCW}=$ hot carcass weight.

${ }^{3} \mathrm{HCW}$ SD $=$ hot carcass weight SD.

${ }^{4}$ Marbling $=$ USDA marbling score $\left(400=\right.$ Slight, $500=$ Small ${ }^{00}$, etc. $)$.

with $2.33 \%$ for the unsorted group. The sorted fall yearlings had a daily DMI of $2.40 \%$ of BW, compared with $2.43 \%$ for unsorted steers.

A significant interaction was observed for $\mathrm{G}: \mathrm{F}(P<0.05)$. The unsorted calf-fed steers were the most efficient, at $0.179 \mathrm{~kg}$ of BW gain $/ \mathrm{kg}$ of intake, which was higher than that of the sorted calf-fed steers $(0.170 \mathrm{~kg}$ of BW gain $/ \mathrm{kg}$ of intake), sorted summer yearlings (0.161 kg of BW gain/ $\mathrm{kg}$ of intake), and unsorted summer yearlings $(0.164 \mathrm{~kg}$ of $\mathrm{BW}$ gain $/ \mathrm{kg}$ of intake). The sorted and unsorted fall yearlings were the least efficient, at 0.153 and $0.147 \mathrm{~kg}$ of BW gain $/ \mathrm{kg}$ of intake, respectively. The unsorted calf-fed steers were the most efficient even though they were the lightest steers that entered the feedlot. As stated above, there was no difference in ADG or DMI for the sorted and unsorted calf-fed steers. These data suggest that the lighter steers that enter the feedlot as calf-fed steers will be more efficient compared with the heavier steers that enter the feedlot as calf-fed steers. Overall, G:F was similar for sorted and unsorted (0.163 vs. $0.161 \mathrm{~kg}$ of BW gain $/ \mathrm{kg}$ of intake) steers across the 3 feeding systems.

There was a difference between years in days on feed for the different feeding periods. During yr 2, the steers in all 3 systems were fed more days compared with yr 1 . This was due to the steers in yr 2 having a lighter average BW at receiving, which carried through the rest of the trial. The steers in yr 2 were marketed at BW similar to steers in yr 1, which required the steers in yr 2 to be fed longer in the feedlot to make up that difference.

\section{Carcass Characteristics}

Carcass weight followed the same pattern as initial feedlot BW (Table $3)$. There was an interaction between feeding period and sorted versus unsorted $(P<0.01)$. The unsorted calf-fed steers had the lowest HCW, at $351 \mathrm{~kg}$. The sorted calf-fed steers had a HCW of $366 \mathrm{~kg}$, which was different from that of the unsorted calf-fed steers. This was similar to the relationship of initial feedlot BW. For the summer yearlings, there was no difference between the sorted and unsorted groups, at 389 and $388 \mathrm{~kg}$, respectively. There was a difference in HCW between the sorted and unsorted fall yearling groups. The sorted group was $22 \mathrm{~kg}$ lighter than the unsorted fall yearlings. Again, this followed the same pattern as the initial feedlot BW. This interaction was expected because of the design of the study. The heaviest steers in the sorted group were sorted into the calf-fed system and the lightest steers were placed into the fall yearling system.

These results were similar to previous research showing that fall yearlings had heavier carcasses compared with calf-fed steers (Jordan, 2000; Sainz and Vernazza Paganini, 2004; Griffin et al., 2007). Griffin et al. (2007) compared calf-fed steers and yearlings over $8 \mathrm{yr}$. They concluded that the yearling steers had an additional $90 \mathrm{~kg}$ of final BW. This was calculated by adding the difference of initial and final BW. In the comparison by Griffin et al. (2007), the calf-fed steers were heavier at receiving, whereas the yearlings were lighter. The final BW was $38 \mathrm{~kg}$ more for the yearlings compared with the calf-fed steers. The initial BW of calffed steers was $52 \mathrm{~kg}$ heavier than that for yearlings, thus resulting in a total of $90 \mathrm{~kg}$ more net final BW that was sold (BW gained). In this study, the sorted yearlings had an additional 108 $\mathrm{kg}$ of $\mathrm{BW}$ that was sold (BW gained) based on initial and final BW compared with the sorted calf-fed steers. The sorted steers from this study would be similar to the steers used in the study by Griffin et al. (2007), with the heavier steers finished as 
calf-fed steers and the lighter steers finished as fall yearlings. In our study, the unsorted yearlings had an additional $46 \mathrm{~kg}$ of $\mathrm{HCW}$, for a total of $112 \mathrm{~kg}$ greater net final BW (gained) compared with that of the calf-fed steers. This indicates that finishing steers as yearlings will allow more $\mathrm{BW}$ to be gained and some extra BW to be sold.

The SD of the HCW was similar to that of the initial feedlot BW, with all 3 sorted groups having numerically lower values compared with the unsorted groups. The sorted calf-fed steers had a 4-kg lower SD compared with that of the unsorted calf-fed steers. The sorted summer yearlings had an 11-kg lower SD. The sorted fall yearlings had a $12-\mathrm{kg}$ lower SD than that of the unsorted fall yearlings.

Carcass weights are important because most packing plants discount carcasses that are heavier than $431 \mathrm{~kg}$ and carcasses that are heavier than $454 \mathrm{~kg}$ (Feuz, 2002; USDA, 2008). There was a significant interaction between the feeding periods and sorted versus unsorted for percentage of carcasses of greater than $431 \mathrm{~kg}$. The unsorted fall yearlings had the highest percentage, at $35.42 \%$ greater than $431 \mathrm{~kg}$, followed by the unsorted summer yearlings, at $10.42 \%$. This was expected because the unsorted summer and fall yearlings were never sorted by BW and contained some of the larger steers at receiving. The unsorted fall yearlings also had the greatest HCW average at the end of the finishing period. The sorted fall yearlings exhibited $6.40 \%$ overweight carcasses, which was not nearly as great as for unsorted fall yearlings and unsorted summer yearlings. There were no differences between the sorted summer yearlings, unsorted calf-fed steers, and sorted calf-fed steers, which exhibited approximately $2 \%$ overweight carcasses.

An interaction was observed between feeding period and sorted versus unsorted $(P<0.01)$ for carcasses of greater than $454 \mathrm{~kg}$. The percentage of unsorted fall yearlings was significantly higher (17.71\%) than the percentage of other groups, which ranged from 0 to $2.08 \%$. These data show that sorting steers into the different feeding systems decreased the number of overweight carcasses.

The other carcass characteristics evaluated were the LM area, 12th-rib backfat thickness, and USDA called marbling. For the LM area, there was a significant interaction $(P<0.01)$. The sorted calf-fed steers had a larger LM area than the unsorted calf-fed steers. The LM area for the sorted calf-fed steers was similar to that of the fall yearlings, which was not different between the sorted and unsorted groups. The sorted and unsorted summer yearlings were not different from the unsorted calf-fed steers.

There was not a significant interaction between feeding period and sorted versus unsorted steers for fat thickness; however, there was a difference between feeding periods. There was no difference between calf-fed steers and summer yearlings. The fat thickness of calf-fed steers averaged $1.36 \mathrm{~cm}$ and that of summer yearlings averaged $1.38 \mathrm{~cm}$. Both of these groups had greater fat thickness than the fall yearlings, which averaged $1.23 \mathrm{~cm}$. This indicates that the calf-fed steers and summer yearlings were finished to a similar fat thickness and that the fall yearlings required more days on feed to be at a similar fat thickness. If the fall yearlings had been fed longer, the number of overweight carcasses would have increased. Marbling scores (400 $=$ Slight $^{00}, 500=$ Small $^{00}$, etc.) were called by a USDA grader at the plant where the steers were slaughtered. No interaction was observed for marbling score; however, there was a difference in feeding period. The calf-fed steers and fall yearlings had similar marbling, with an average score of 569 and 577, respectively. Krehbiel et al. (2000), Sainz and Vernazza Paganini (2004), and Griffin et al. (2007) also showed that calf-fed steers and fall yearlings had similar USDA called marbling scores. The scores of calf-fed steers and fall yearlings were higher than those of summer yearlings, with an average score of 515 . The steers finished during the summer months did not grade as well as those finished during the winter-spring or fall.

\section{Grazing Periods}

Even though steers were managed as 1 group during winter and summer grazing, performance for the winter and summer grazing periods was retrospectively evaluated using the pen assignment at feedlot entry as the experimental unit. Average daily gains from the winter and summer grazing periods were calculated for the summer and fall yearlings (Table 4). There was a difference in ADG for steers that grazed cornstalks in yr 1 and 2. In yr 1, steers had less ADG compared with steers in yr $2(0.52$ vs. $0.58 \mathrm{~kg} / \mathrm{d}$ ). These BW gains were somewhat less than those reported by Jordan (2000), who had a rate of BW gain of $0.77 \mathrm{~kg} / \mathrm{d}$ by supplementing steers with $2.27 \mathrm{~kg} \mathrm{SB} /$ animal per day. The differences in BW gain between the 2 studies could have been due to the quality of corn residue grazed or the winter weather. The summer yearlings then grazed bromegrass for 35 and $48 \mathrm{~d}$ in yr 1 and 2 , respectively. In yr 1 , the summer yearlings had an ADG of $0.61 \mathrm{~kg} / \mathrm{d}$. In yr 2 , the ADG was $0.07 \mathrm{~kg} / \mathrm{d}$. The fall yearlings also followed the same pattern. The fall yearlings for yr 1 had an ADG of $0.81 \mathrm{~kg} / \mathrm{d}$ compared with $0.31 \mathrm{~kg} / \mathrm{d}$ for yr 2 . Folmer et al. (2008) had a summer ADG for long yearlings of $0.79 \mathrm{~kg} / \mathrm{d}$. Year 1 in the current study was similar, but yr 2 had a much smaller ADG on grass. The poor ADG in yr 2 resulted in the steers in the summer and fall yearling systems being fed longer in the feedlot. Reasons for the poor pasture BW gains in yr 2 are not apparent. Shain et al. (2005) indicated that maximizing grazing BW gain had the greatest effect on reducing the slaughter breakeven cost. The current study also emphasizes the need for good pasture management and BW gain to keep production costs minimal. 


\section{Table 4. Grazing BW gains during the backgrounding phase of the systems for both years based on feeding period}

\begin{tabular}{lccccc} 
& \multicolumn{2}{c}{ yr 1 } & & \multicolumn{2}{c}{ yr 2 } \\
\cline { 2 - 3 } \cline { 5 - 6 } Item & Summer $^{1}$ & Fall $^{2}$ & & Summer $^{1}$ & Fall $^{2}$ \\
\hline Initial BW, ${ }^{3} \mathrm{~kg}$ & 271 & 246 & & 246 & 240 \\
${\text { Grass BW, }{ }^{4} \mathrm{~kg}}$ & 352 & 323 & & 340 & 327 \\
Feedlot BW, ${ }^{5} \mathrm{~kg}$ & 374 & 443 & & 345 & 372 \\
Winter ADG, kg/d & 0.53 & 0.51 & & 0.60 & 0.56 \\
Summer ADG, kg/d & 0.61 & 0.81 & & 0.07 & 0.31 \\
\hline
\end{tabular}

${ }^{1}$ Steers that were finished in the summer yearling system.

${ }^{2}$ Steers that were finished in the fall yearling system.

${ }^{3}$ Initial BW at the time of receiving in the fall.

${ }^{4} \mathrm{BW}$ at the end of cornstalk grazing in the spring and beginning of summer grazing.

${ }^{5} \mathrm{BW}$ at the end of summer grazing and the beginning of the finishing period.

\section{IMPLICATIONS}

Results from this study indicate that sorting steers into different feeding periods based on BW will decrease variation in initial feedlot BW and HCW when steers are slaughtered. Sorting steers into different feeding periods based on BW reduced the number of overweight carcasses among summer and fall yearlings. These data also show that lighter calf-fed steers were more efficient than heavier calf-fed steers, but sorted and unsorted steers over the 3 systems had equal G:F. The data also show that calf-fed steers were more efficient compared with fall yearlings; however, fall yearlings had greater ADG compared with calf-fed steers, with summer yearlings being intermediate for G:F and ADG. It has been recommended that steers be sorted into different feeding periods based on BW. These data support that recommendation because sorting steers by
BW decreased the SD for HCW and the percentage of overweight carcasses without affecting the performance of the steers.

\section{LITERATURE CITED}

Boggs, D. L., and R. A. Merkel. 1993. Beef carcass evaluation, grading, and pricing. p. 105 in Live Animal Caracss Evaluation and Selection Manual. D. L. Boggs and R. A. Merkel, ed. Kendel/Hunt Publishing Co., Dubuque, IA.

Dolezal, H. G., J. D. Tatum, and F. L. William Jr. 1993. Effects of feeder cattle frame size, muscle thickness, and age class on days fed, weight, and carcass composition. J. Anim. Sci. 71:2975.

Feuz, D. M. 2002. A simulated market analysis of altering days on feed and marketing cattle on specific value-based price grids. Nebr. Beef Rep. MP 79-A:39.

Folmer, J. D., W. A. Griffin, C. N. Macken, M. P. Blackford, T. J. Klopfenstein, and G. E. Erickson. 2008. Effects of intensive winter management, partial season grazing, and sorting on performance and economics of a long yearling steer production system. Prof. Anim. Sci. 24:411.
Griffin, W. A., T. J. Klopfenstein, G. E. Erickson, D. M. Feuz, J. C. MacDonald, and D. J. Jordon. 2007. Comparison of performance and economics of a long-yearling and calf-fed system. Prof. Anim. Sci. 23:490.

Jordan, D. J. 2000. Performance and slaughter breakeven analysis of calf and yearling systems and compensatory growth. PhD Diss. Univ. of Nebraska, Lincoln.

Krehbiel, C. R., K. K. Kreikemeier, and C. L. Ferrell. 2000. Influence of Bos indicus crossbreeding and cattle age on apparent utilization of a high grain diet. J. Anim. Sci. 78:1641.

Lewis, M., T. Klopfensein, G. A. Pfeifer, and R. A. Stock. 1989. Forage vs. grain finishing systems and the fate of increased weaning weight due to an increased level of milk. Nebraska Beef Rep. MP 54:29.

Oltjen, J. W., and J. L. Beckett. 1996. Role of ruminant livestock in sustainable agricultural systems. J. Anim. Sci. 74:1406.

Sainz, R. D., and R. F. Vernazza Paganini. 2004. Effects of grazing and feeding periods on performance and carcass traits of beef steers. J. Anim. Sci. 82:292.

Shain, D. H., T. J. Klopfenstein, R. A. Stock, B. A. Vieselmeyer, and G. E. Erickson. 2005. Evaluation of grazing alternate summer and fall forages in extensive beef cattle production systems. Prof. Anim. Sci. 21:390.

Turgeon, O. A. 1984. Impact of high forage growing systems on finishing performance and compensatory growth. PhD Diss. Univ. of Nebraska, Lincoln.

USDA. 2008. Area weekly weighted average direct slaughter cattle - Premiums and discounts. http://www.ams.usda.gov/mnreports/ lm_ct169.txt Accessed Aug. 2008.

Van Soest, P. J. 1994. Nutritional Ecology of the Ruminant. 2nd ed. Cornell Univ. Press, Ithaca, NY.

Vieselmeyer, B. A. 1993. Production and economic interactions of extensive beef production systems. MS Thesis. Univ. of Nebraska, Lincoln. 